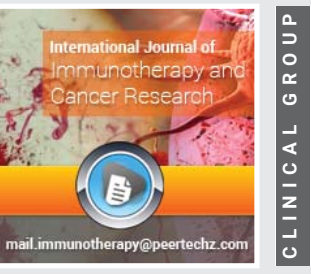

\title{
Understanding immunotherapy and its management
}

\author{
Nadiminti Rajesh Kumar* and Sajid Alvi ${ }^{2}$ \\ ${ }^{1}$ Research Scholar, Lotus Business School, Pune, India \\ 2Director, DIMR, Pune, India
}

Received: 04 January, 2021

Accepted: 11 January, 2021

Published: 12 January, 2021

*Corresponding authors: Nadiminti Rajesh Kumar Research Scholar, Lotus Business School, Pune, India, Tel: 8125245744; E-mail: rajeshkumarrx32@gmail.com

Keywords: Immunotherapy; PD-1/PD-L1 mechanism; Tumor stroma role in PD-1/PD-L1; Immune resistance; Challenges and new approach; Combination immune therapy

https://www.peertechz.com

Check for updates

\begin{abstract}
A few tumours are exceptionally stubborn to oral chemotherapy. The endurance of tumours in a few cases is helped by checkpoint immunomodulation to keep up the unevenness between resistant reconnaissance and disease cell division. Checkpoint counteracting agent inhibitors, for example, against PD-1/PD-L1, are another class of inhibitors that capacity has tumour stifling element using a balance of resistant cell/tumour cell communication. These checkpoint inhibitors are quickly turning into a profoundly encouraging malignancy helpful methodology that shows astounding antitumor reaction with restricted symptoms. As of late over four checkpoint inhibitors have been utilized for focusing on PD-1, PD-L1 and CTLA-4. Despite the immense achievement and viability of hostile to PD treatment reaction, it is restricted to explicit kind of malignant growths, which credits to the lacking and heterogeneous articulation of PD- 1 in the tumour miniature condition. Thus, we audit the current extent of the PD-1/PD-L1 instrument function in tumour invulnerable avoidance and helpful result for malignant growth treatment.
\end{abstract}

\section{Abbreviations}

PL /PL-1: Programmed Cell / Programmed Cell-1; CTLA4: Cytotoxic $\mathrm{T}$ Lymphocyte Associated Protein-4; ACT: Ascending T Cell Treatment; HPV: Human Papilloma Virus; ASCO: American Society of Clinical Oncology Journal; IMD: Different Immunomodulator; CAR -T-Cell: Chimeric Antigen Receptor-T cell; FDA: Food Drug Association

\section{Introduction}

Immunotherapy is a kind of malignancy therapy that enables your safe framework to battle disease. The resistant framework enables your body to battle contaminations and different infections. It is comprised of white platelets and organs and tissues of the lymph framework. Immunotherapy is a sort of natural treatment. Natural treatment is a sort of therapy that utilizes substances produced using living life forms to treat malignant growth. Immunotherapy is a therapy that utilizes certain pieces of an individual resistant framework to battle illnesses, for example, malignancy this should be possible in two different ways. Stimulating your insusceptible framework to work more diligently or more brilliant to assault malignancy cells. Giving you insusceptible framework parts, for example, man-made safe framework proteins. In the most recent couple of decade, immunotherapy has become a significant piece of treating a few kinds of malignant growth. Fresher kinds of safe therapies are currently being contemplated, and they will affect how we treat malignant growth later on. Immunotherapy incorporates treatment that works in various manners. Some lift the body insusceptible framework in an overall way. Others help train the invulnerable framework to assault disease cells explicitly. The immune framework works better for certain kinds of disease than for other people. It's utilized without anyone else for a portion of these tumours, yet for other people, it appears to work better when utilized with different kinds of treatment.

\section{Current trends}

There are a few developing patterns in immuno-oncology, including checkpoint inhibitors and Assenting T-Cell Treatment (ACT). Invulnerable checkpoint segments, for example, Cytotoxic T Lymphocyte antigen 4 (CTLA-4) and customized cell Passing 1 (PD-1) and its ligand (PD-L1)- are communicated on tumour-penetrating lymphocytes and numerous kinds of tumour cells, and they permit dangerous cells to sidestep cytotoxic insusceptible reactions. Ipilimumab, a neutralizer focusing on CTLA-4 endorsed by the FDA for use in patients with melanoma, represses this cycle and encourages $\mathrm{T}$-cell actuation against tumour cells. Antibodies focusing on PD-1 and PD-L1 are likewise being tried in stage III preliminaries 
against a few sorts of tumours. This year in Japan nivolumab turned into the first PD-1 inhibitor to accomplish administrative endorsement in melanoma. Promising outcomes have likewise been posted for the trial against PD-L1 counteracting agent MPDL3280A in melanoma, cellular breakdown in the lungs and bladder malignant growth. ACT, T cells enacted against tumour-explicit antigens are confined from the patient, extended ex vivo, and afterwards once again introduced into the patient. A stage I study introduced at the 2014 ASCO Annual Meeting tried Human Papillomavirus (HPV)- explicit T cells in patients with metastatic cervical malignant growth and created a few sturdy complete reactions.

\section{Literature review}

Cancer has clarified on the essential component of the insusceptible framework as it identifies with the disease has been expanding quickly which zeroed in on inspecting flow information and future bearings of exploration identified with tumour immunology and malignant growth immunotherapy, remembering meetings for inborn invulnerability, versatile resistance, helpful methodologies (dendritic cells, receptive $\mathrm{T}$-cell treatment, against tumour antibodies, malignancy immunizations and safe checkpoint barricade), challenge to driving an enemy of tumor safe reaction, observing safe reactions and the eventual fate of immunotherapy clinical preliminary plan [1]. Immunotherapy has clarified the advancing function of immunotherapy medicines in India alongside the security and adequacy identified with kinds of immunotherapy medicines accessible [2]. Cancer Immunotherapy gave a short survey on the history prospects and difficulties ahead on malignant growth immunotherapy [3].

Cancer Immunotherapy examined the present and eventual fate of disease immunotherapy: A tumour miniature ecological point of view. Despite accomplishment in focusing on nontumour cell segments, including insusceptible checkpoint blockage, focussing on a solitary invulnerable suppressive objective is insufficient in most of the patient with the malignant growth. Following obstructing or hindering of one invulnerable suppressive sign, the tumour will repay through another component to produce the opposition and decrease the proficiency of immunotherapy. The relationship between the heterogeneity of the tumour microenvironment and the immunotherapy reaction stays a critical test. Later on, immunotherapy might be needed to be customized for every patient with the disease as per the tumour microenvironment The utilization of novel safe biomarkers [4] PD-L1 examined on the improvement of resistant checkpoint inhibitor has changed the therapy worldview for cutting edge diseases across numerous tumour type. Notwithstanding promising and now and then strong reactions in a subset of patients, most [5]. Immunotherapy has clarified the expanding utilization of different Immunomodulatory (IMD) agence for malignant growth treatments (eg: antibodies focusing on a resistant checkpoint, by explicit antibodies and illusory antigen receptor ((CAR)- T-cell). The advantage showed as far as long-haul reactions and infection control by endorsed IMD treatments and significance of adequately executing these treatment methodologies [6].
Cost of Immunotherapy in India: Its cost around 1 lakh to 1.3 Lakh for one treatment of Immunotherapy in India. In like clockwork, another treatment is needed to been given to the patient, if necessary. The expense of immunotherapy in India is just about $8-10$ times lower than the expense of immunotherapy in western nations though there is no adjustment in the outcome and the cycle of treatment of both the parts. Cancer Immunotherapy isn't advanced in India due to the reasoning and their perspectives on natively constructed sub-atomic medications and treatments. Along these lines, the absence of prevalence is one of the explanation that why immunotherapy isn't advanced in India. Sometimes, it is seen that the immunotherapy sets aside a long-range of effort to regard malignancy when contrasted with other treatment techniques. Immunotherapy doesn't take a shot by any stretch of the imagination. Cost is likewise an issue in a portion of the cases [7-15].

\section{Objectives of a research}

Immunotherapy is the most evolving treatment for cancer management.

a. To find out the institute-wise protocol

b. To find out how do doctors choose different immune therapy

c. To understand the different $\{P D-1$ and PDL-1\} Immunotherapy agents.

d. To understand the challenges faced by patients

\section{Research methodology}

Type of research: Exploratory and Descriptive

Research design: Qualitative and Quantitative

Sample size -80

The present work includes mainly three steps

1. To prepare a questionnaire for doctors

2. Collect the responses from the Doctors

3. Analyse the results and to give the conclusion

Hypothesis: Every hospital has a cancer immunotherapy treatment protocol however poor adherence to protocol.

\section{Data analysis}

\begin{tabular}{|l|c|c|c|c|c|c|}
\hline \multicolumn{7}{|c|}{ Descriptive Statistics } \\
\hline \multicolumn{1}{|c|}{ Hospital Name } & N & Minimum & Maximum & Mean & Std. Deviation \\
\cline { 2 - 7 } & 80 & 1 & 4 & 2.51 & 1.079 \\
\hline $\begin{array}{l}\text { 1. How do you choose therapy } \\
\text { for patients? (order of priority) }\end{array}$ & 80 & 1 & 3 & 2.16 & .803 \\
\hline $\begin{array}{l}\text { 2. Why do you choose } \\
\text { immunotherapy? }\end{array}$ & 80 & 1 & 2 & 1.48 & .503 \\
\hline $\begin{array}{l}\text { 3. What is your way of treatment } \\
\text { of immunotherapy? }\end{array}$ & 80 & 1 & 2 & 1.41 & .495 \\
\hline
\end{tabular}

Citation: Kumar NR, Alvi S (2021) Understanding immunotherapy and its management Int J Immunother Cancer Res 7(1): 001-007. 
4. On what parameters you choose different immunotherapy molecules?

5. What are your goals for immunotherapy when you prescribe for a patient? 6. How long does it take immunotherapy to start?

7. Start and what is the duration of therapy?

7. Which medicine has a good activity of immune checkpoint? 80

Generaly, prescribe PDL

inhibitors

Generally, prescribe PDL-1

inhibitors

8. What are the side effects of

immunotherapy and how do you 80

control them?

9. What is the success rate of

(\%) immunotherapy and how

effective you feel?

\begin{tabular}{|l|l|l|l|l|l|}
\hline 10. would you like to suggest? & 80 & 1 & 3 & 1.94 & .785 \\
\hline
\end{tabular}

Valid N (listwise)

80

Case Processing Summary for cross tabs

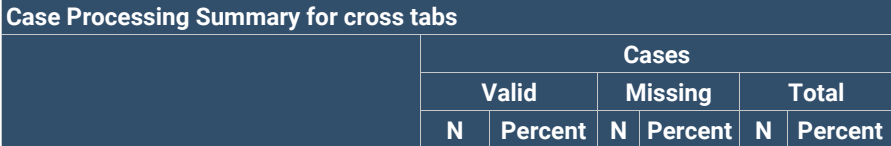

1. How do you choose therapy for

patients? (order of priority)

\begin{tabular}{|l|l|l|l|l|l}
\hline 80 & $100.0 \%$ & 0 & $0.0 \%$ & 80 & $100.0 \%$
\end{tabular}

2. Why do you choose

immunotherapy?

3. What is your way of treatment of

immunotherapy?

4. On what parameters you choose

different immunotherapy molecules?

5. What are your goals for

\begin{tabular}{|l|l|l|l|l|l|l|} 
immunotherapy when you prescribe & 80 & $100.0 \%$ & 0 & $0.0 \%$ & 80 & $100.0 \%$
\end{tabular}

for a patient?

6. How long does it take

immunotherapy to start?

\begin{tabular}{ll|l|l|l|l|l} 
7. what is the duration of therapy? & 80 & $100.0 \%$ & 0 & $0.0 \%$ & 80 & $100.0 \%$
\end{tabular}

\begin{tabular}{|l|l|l|l|l|l|l|}
\hline 8. Which medicine has a good activity & 80 & $100.0 \%$ & 0 & $0.0 \%$ & 80 & $100.0 \%$
\end{tabular}

of immune checkpoint?

8.1Generally, prescribe PDL inhibitors

8.2Generally, prescribe PDL-1

inhibitors

9. What are the side effects of immunotherapy and how do you control them?

10. What is the success rate of (\%) immunotherapy and how effective you feel?

11. would you like to suggest any other therapies?

\begin{tabular}{|l|l|l|l|l|l}
\hline 80 & $100.0 \%$ & 0 & $0.0 \%$ & 80 & $100.0 \%$ \\
\hline
\end{tabular}

\begin{tabular}{|l|l|l|l|l|l}
80 & $100.0 \%$ & 0 & $0.0 \%$ & 80 & $100.0 \%$
\end{tabular}

\begin{tabular}{l|l|l|l|l|l}
80 & $100.0 \%$ & 0 & $0.0 \%$ & 80 & $100.0 \%$
\end{tabular}

\begin{tabular}{l|l|l|l|l|l}
80 & $100.0 \%$ & 0 & $0.0 \%$ & 80 & $100.0 \%$
\end{tabular}

\begin{tabular}{|l|l|l|l|l|l|}
\hline 80 & $100.0 \%$ & 0 & $0.0 \%$ & 80 & $100.0 \%$ \\
\hline
\end{tabular}

\begin{tabular}{l|l|l|l|l|l}
80 & $100.0 \%$ & 0 & $0.0 \%$ & 80 & $100.0 \%$
\end{tabular}

\begin{tabular}{l|l|l|l|l|l}
80 & $100.0 \%$ & 0 & $0.0 \%$ & 80 & $100.0 \%$
\end{tabular}

\begin{tabular}{|l|l|l|l|l|l}
\hline 80 & $100.0 \%$ & 0 & $0.0 \%$ & 80 & $100.0 \%$
\end{tabular}

1. How do you choose therapy for patients?(order of priority)
\begin{tabular}{|c|c|c|c|c|c|}
\hline & & $\mathbf{2}$ & 3 & \\
\hline & Apollo & 3 & 6 & 9 & 18 \\
\hline \multirow{3}{*}{ Hospital Name } & Basavaturakam Indo american & 5 & 6 & 10 & 21 \\
\hline & Omega & 7 & 8 & 8 & 23 \\
\hline & Yashodha & 5 & 7 & 6 & 18 \\
\hline & Total & 20 & 27 & 33 & 80 \\
\hline
\end{tabular}

This table allows us to understand that Hospitals VS Choosing therapy for patients to 1, 2 and 3 .

\section{Hypothesis}

Ho = There is no significant association between Choosing therapy and Hospitals

$\mathrm{H} 1$ = There is a significant association between Choosing therapy and Hospitals.

\begin{tabular}{|c|c|c|c|}
\hline \\
\hline \multicolumn{4}{|c|}{$\begin{array}{l}\text { Chi-Square Tests } \\
\begin{array}{l|l|l|l} & \text { Value } & \text { df } & \text { Asymp. Sig (2-sided }\end{array}\end{array}$} \\
\hline Pearson Chi-Square & $2.202^{\mathrm{a}}$ & 6 & .900 \\
\hline $\mathrm{N}$ of Valid Cases & 80 & & \\
\hline
\end{tabular}

When reading this table we are interested in the results of the "Pearson Chi-Square" row.

We can see here that $\chi^{\Lambda^{2}}=2.202, p=0.90$. This tells us that there is no statistically significant association between Choosing therapy and Hospitals.

\section{Why do you choose immunotherapy?}

\begin{tabular}{|c|c|c|c|c|}
\hline & & $\mathbf{1}$ & $\mathbf{2}$ & \\
\hline & Apollo & 10 & 8 & 18 \\
\hline \multirow{3}{*}{ Hospital Name } & Basavaturakam Indo american & 10 & 11 & 21 \\
\cline { 2 - 6 } & Omega & 11 & 12 & 23 \\
\hline & Yashodha & 11 & 7 & 18 \\
\hline & Total & 42 & 38 & 80 \\
\hline
\end{tabular}

This table allows us to understand that Hospitals VS why do you Choose immunotherapy to 1 and 2 .

\section{Hypothesis}

$\mathrm{Ho}_{2}=$ There is no significant association between Choosing immunotherapy and Hospitals

$\mathrm{H} 1_{2}=$ There is a significant association between Choosing immunotherapy and Hospitals.

\begin{tabular}{|c|c|c|c|}
\hline \multicolumn{4}{|l|}{ Chi-Square Tests } \\
\hline & Value & Df & Asymp. Sig (2-sided) \\
\hline Pearson Chi-Square & $1.005^{\mathrm{a}}$ & 3 & .800 \\
\hline $\mathrm{N}$ of Valid Cases & 80 & & \\
\hline
\end{tabular}

When reading this table we are interested in the results of the "Pearson Chi-Square" row.

We can see here that $\chi^{\Lambda^{2}}=1.005, p=0.80$. This tells us that there is no statistically significant association between Choosing immunotherapy and Hospitals.

3. What is your way of treatment of immunotherapy?
\begin{tabular}{|c|c|c|c|c|}
\hline & & 1 & 2 & \\
\hline & Apollo & 14 & 4 & 18 \\
\hline & Basavaturakam Indo American & 16 & 5 & 21 \\
\hline \multirow{3}{*}{ Hospital Name } & Omega & 9 & 14 & 23 \\
\hline & Yashodha & 8 & 10 & 18 \\
\hline & Total & 47 & 33 & 80 \\
\hline
\end{tabular}

This table allows us to understand that Hospitals VS treatment of immunotherapy to 1 and 2. 


\section{Hypothesis}

$\mathrm{Ho}_{3}=$ There is no significant association between treatment of immunotherapy and Hospitals

$\mathrm{H} 1_{3}=$ There is a significant association between treatment of immunotherapy and Hospitals.

\begin{tabular}{l|c|c|c|}
\hline \multicolumn{4}{|l|}{ Chi-Square Tests } \\
\hline & Value & df & $\begin{array}{c}\text { Asymp.Sign } \\
(2-\text {-sided) }\end{array}$ \\
\hline Pearson Chi-Square & $10.498^{\mathrm{a}}$ & 3 & .015 \\
\hline $\mathrm{N}$ of Valid Cases & 80 & & \\
\hline
\end{tabular}

When reading this table we are interested in the results of the "Pearson Chi-Square" row.

We can see here that $\chi^{\Lambda^{2}}=10.498, p=0.15$. This tells us that there is a statistically significant association between treatment of immunotherapy and Hospitals.

\begin{tabular}{|c|c|c|c|c|c|c|c|c|}
\hline \multicolumn{9}{|c|}{ 4. On what parameters you choose different immunotherapy molecules? } \\
\hline & & 1 & 2 & 3 & 4 & 5 & 6 & \\
\hline \multirow{4}{*}{$\begin{array}{c}\text { Hospital } \\
\text { Name }\end{array}$} & Apollo & 1 & 3 & 0 & 1 & 8 & 5 & 18 \\
\hline & Basavaturakam Indo American & 0 & 3 & 2 & 5 & 5 & 6 & 21 \\
\hline & Omega & 1 & 4 & 3 & 5 & 5 & 5 & 23 \\
\hline & Yashodha & 3 & 2 & 4 & 2 & 4 & 3 & 18 \\
\hline \multicolumn{2}{|r|}{ Total } & 5 & 12 & 9 & 13 & 22 & 19 & 80 \\
\hline
\end{tabular}

This table allows us to understand that Hospitals VS different immunotherapy molecules to 1, 2, 3, 4, 5 and 6 .

\section{Hypothesis}

$\mathrm{Ho}_{4}=$ There is no significant association between immunotherapy molecules and Hospitals

$\mathrm{H} 1_{4}=$ There is a significant association between immunotherapy molecules and Hospitals.

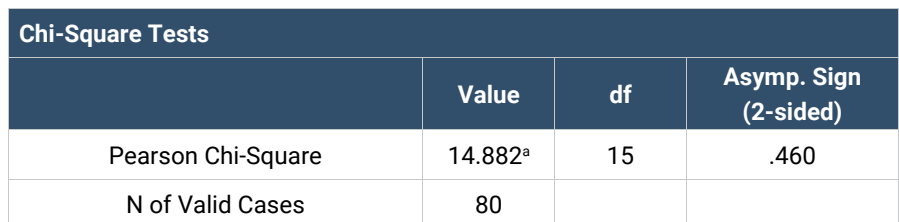

When reading this table we are interested in the results of the "Pearson Chi-Square" row.

We can see here that $\chi^{\Lambda^{2}}=14.882, p=0.46$. This tells us that there is no statistically significant association between immunotherapy molecules and Hospitals.

5. What are your goals for immunotherapy when you prescribe for a
patient?
\begin{tabular}{|c|c|c|c|c|c|c|}
\hline & 1 & 2 & 3 & 4 & Total \\
\hline \multirow{3}{*}{ Hospital } & Apollo & 6 & 2 & 6 & 4 & 18 \\
\hline Name & Basavaturakam Indo American & 11 & 6 & 2 & 2 & 21 \\
\hline & Omega & 6 & 5 & 6 & 6 & 23 \\
\hline & Yashodha & 3 & 6 & 5 & 4 & 18 \\
\hline & Total & 26 & 19 & 19 & 16 & 80 \\
\hline
\end{tabular}

This table allows us to understand that Hospitals VS when you prescribe for a patient for immunotherapy to 1, 2, 3 and 4 .

\section{Hypothesis}

$\mathrm{Ho}_{5}=$ There is no significant association between when you prescribe for a patient and Hospitals

$\mathrm{H} 1_{6}=$ There is a significant association between when you prescribe for a patient and Hospitals.

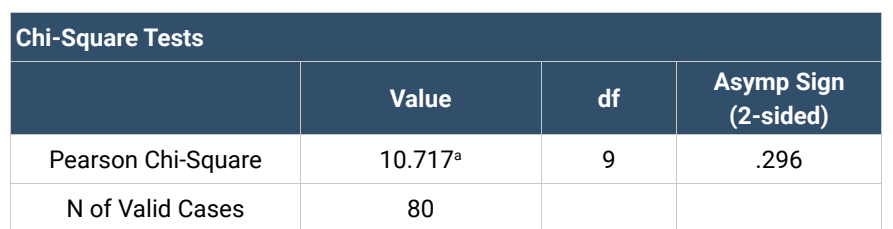

When reading this table we are interested in the results of the "Pearson Chi-Square" row.

We can see here that $\chi^{\Lambda^{2}}=10.717, p=0.29$. This tells us that there is no statistically significant association between when you prescribe for a patient for immunotherapy and Hospitals.

\begin{tabular}{|c|c|c|c|c|c|c|}
\hline \multicolumn{7}{|c|}{ 6.How long does it take immunotherapy to start? } \\
\hline & & 1 & 2 & 3 & 4 & \\
\hline \multirow{4}{*}{ Hospital Name } & Apollo & 4 & 8 & 1 & 5 & 18 \\
\hline & Basavaturakam Indo merican & 5 & 8 & 2 & 6 & 21 \\
\hline & Omega & 9 & 5 & 2 & 7 & 23 \\
\hline & Yashodha & 3 & 9 & 3 & 3 & 18 \\
\hline \multicolumn{2}{|r|}{ Total } & 21 & 30 & 8 & 21 & 80 \\
\hline
\end{tabular}

This table allows us to understand that Hospitals VS How long does it take immunotherapy to start to $1,2,3$ and 4 .

\section{Hypothesis}

$\mathrm{Ho}_{7}=$ There is no significant association between immunotherapy to start and Hospitals

$\mathrm{H}_{7}=$ There is a significant association between immunotherapy to start and Hospitals.

\begin{tabular}{|c|c|c|c|}
\hline Chi-Square Tests \\
\hline & Value & df & $\begin{array}{c}\text { Asymp. Sign } \\
\text { (2-sided) }\end{array}$ \\
\hline Pearson Chi-Square & $6.791^{\text {a }}$ & 9 & .659 \\
\hline N of Valid Cases & 80 & & \\
\hline
\end{tabular}

When reading this table we are interested in the results of the "Pearson Chi-Square" row.

We can see here that $\chi^{\Lambda^{2}}=6.791, p=0.65$. This tells us that there is no statistically significant association between How long does it take immunotherapy to start and Hospitals.

7. What is the duration of therapy?
\begin{tabular}{|l|c|c|c|c|c|}
\hline & Apollo & 1 & 2 & 3 & \\
\hline \multirow{3}{*}{ Hospital Name } & 7 & 7 & 4 & 18 \\
\hline \multirow{3}{*}{ Basavaturakam Indo american } & 4 & 4 & 13 & 21 \\
\hline & Omega & 6 & 8 & 9 & 23 \\
\hline & Yashodha & 4 & 6 & 8 & 18 \\
\hline & Total & 21 & 25 & 34 & 80 \\
\hline
\end{tabular}

This table allows us to understand that Hospitals VS the duration of therapy to 1,2 and 3. 


\section{Hypothesis}

$\mathrm{Ho}_{8}=$ There is no significant association between duration of therapy and Hospitals

$\mathrm{H} 1_{8}=$ There is a significant association between duration of therapy and Hospitals

\begin{tabular}{|c|c|c|c|}
\multicolumn{1}{|l|}{ Chi-Square Tests } \\
\hline Pearson Chi-Square & $6.755^{\mathrm{a}}$ & 6 & $\begin{array}{c}\text { Asymp. Sign } \\
\text { (2-sided) }\end{array}$ \\
\hline $\mathrm{N}$ of Valid Cases & 80 & & .344 \\
\hline
\end{tabular}

When reading this table we are interested in the results of the "Pearson Chi-Square" row.

We can see here that $\chi^{\Lambda^{2}}=6.755, p=0.34$. This tells us that there is no statistically significant association between the duration of therapy and Hospitals.

8. Which medicine has a good activity of immune checkpoint?
\begin{tabular}{|c|c|c|c|c|c|c|}
\hline & Apollo & 1 & 2 & 3 & 4 & Total \\
\hline \multirow{4}{*}{ Hospital Name } & 5 & 4 & 5 & 4 & 18 \\
\cline { 2 - 8 } & Basavaturakam Indo american & 9 & 2 & 6 & 4 & 21 \\
\cline { 2 - 8 } & Omega & 3 & 8 & 9 & 3 & 23 \\
\hline \multirow{2}{*}{ Yashodha } & 4 & 4 & 8 & 2 & 18 \\
\hline & Total & 21 & 18 & 28 & 13 & 80 \\
\hline
\end{tabular}

This table allows us to understand that Hospitals VS good activity of immune checkpoint to 1, 2, 3 and 4 .

\section{Hypothesis}

$\mathrm{Ho}_{9}=$ There is no significant association between the good activity of immune checkpoint and Hospitals

$\mathrm{H} 1_{9}=$ There is a significant association between the good activity of immune checkpoint and Hospitals

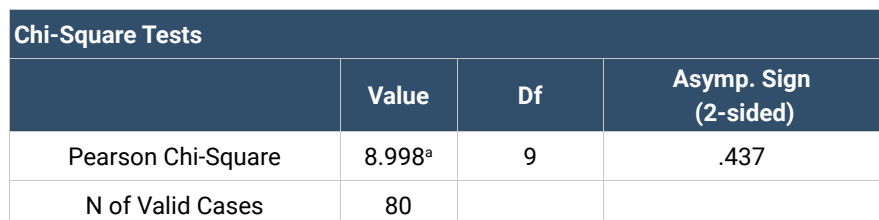

When reading this table we are interested in the results of the "Pearson Chi-Square" row.

We can see here that $\chi^{\Lambda^{2}}=8.998, p=0.43$. This tells us that there is no statistically significant association between medicines has a good activity of immune checkpoint and Hospitals.

8.1 Generally, prescribe PDL inhibitors
\begin{tabular}{|c|c|c|c|c|c|c|}
\hline & & 1 & 2 & 3 & 4 & \\
\hline \multirow{3}{*}{ Hospital Name } & Apollo & 4 & 6 & 2 & 6 & 18 \\
\cline { 2 - 8 } & Basavaturakam Indo american & 9 & 2 & 6 & 4 & 21 \\
\cline { 2 - 8 } & Omega & 6 & 6 & 5 & 6 & 23 \\
\cline { 2 - 8 } & Yashodha & 6 & 8 & 3 & 1 & 18 \\
\hline & Total & 25 & 22 & 16 & 17 & 80 \\
\hline
\end{tabular}

This table allows us to understand that Hospitals VS Generally, prescribe PDL inhibitors to 1, 2, 3 and 4 .

\section{Hypothesis}

$\mathrm{Ho}_{10}=$ There is no significant association between Generally, prescribe PDL inhibitors and Hospitals

$\mathrm{H} 1_{10}=$ There is a significant association between Generally, prescribe PDL inhibitors and Hospitals

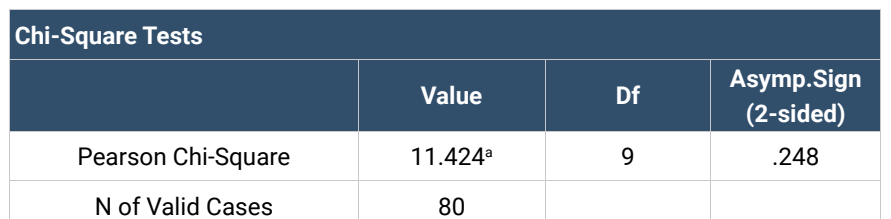

When reading this table we are interested in the results of the "Pearson Chi-Square" row.

We can see here that $\chi^{\Lambda^{2}}=11.424, p=0.24$. This tells us that there is no statistically significant association between Generally, prescribe PDL inhibitors and Hospitals.

\begin{tabular}{|c|c|c|c|c|c|c|}
\hline & & 1 & 2 & 3 & 4 & \\
\hline \multirow{4}{*}{ Hospital Name } & Apollo & 6 & 4 & 2 & 6 & 18 \\
\hline & Basavaturakam Indo american & 6 & 6 & 4 & 5 & 21 \\
\hline & Omega & 4 & 5 & 7 & 7 & 23 \\
\hline & Yashodha & 4 & 4 & 7 & 3 & 18 \\
\hline \multicolumn{2}{|r|}{ Total } & 20 & 19 & 20 & 21 & 80 \\
\hline
\end{tabular}

This table allows us to understand that Hospitals VS Generally, prescribe PDL-1 inhibitors to $1,2,3$ and 4 .

\section{Hypothesis}

$\mathrm{Ho}_{11}=$ There is no significant association between generally, prescribe PDL-1 inhibitors and Hospitals

$\mathrm{H} 1_{11}=$ There is a significant association between generally, prescribe PDL-1 inhibitors and Hospitals.

\begin{tabular}{|c|c|c|c|}
\hline \multicolumn{4}{|l|}{ Chi-Square Tests } \\
\hline & Value & Df & $\begin{array}{l}\text { Asymp. Sign } \\
\text { (2-sided) }\end{array}$ \\
\hline Pearson Chi-Square & $5.997^{a}$ & 9 & .740 \\
\hline $\mathrm{N}$ of Valid Cases & 80 & & \\
\hline
\end{tabular}

When reading this table we are interested in the results of the "Pearson Chi-Square" row.

We can see here that $\chi^{\Lambda^{2}}=5.997, p=0.74$. This tells us that there is no statistically significant association between Generally, prescribe PDL-1 inhibitors and Hospitals.

9. What are the side effects of immunotherapy and how do you control them?
\begin{tabular}{|c|c|c|c|c|c|c|}
\hline & Apollo & $\mathbf{1}$ & $\mathbf{2}$ & $\mathbf{3}$ & $\mathbf{4}$ & Total \\
\hline \multirow{3}{*}{ Hospital Name } & 4 & 7 & 5 & 2 & 18 \\
\cline { 2 - 8 } & Basavaturakam Indo American & 4 & 9 & 5 & 3 & 21 \\
\cline { 2 - 8 } & Omega & 7 & 5 & 10 & 1 & 23 \\
\hline \multirow{2}{*}{ Yashodha } & 5 & 2 & 6 & 5 & 18 \\
\hline \multirow{2}{*}{ Total } & 20 & 23 & 26 & 11 & 80 \\
\hline
\end{tabular}

This table allows us to understand that Hospitals VS side effects of immunotherapy and control to 1, 2, 3 and 4 . 


\section{Hypothesis}

$\mathrm{Ho}_{12}=$ There is no significant association between side effects of immunotherapy and control and Hospitals

$\mathrm{H} 1_{12}=$ There is a significant association between side effects of immunotherapy and control and Hospitals

\begin{tabular}{|c|c|c|c|}
\hline \multicolumn{1}{|l|}{ Chi-Square Tests } \\
\hline Pearson Chi-Square & $10.737^{a}$ & 9 & .294 \\
\hline $\mathrm{N}$ of Valid Cases & 80 & & \\
\hline
\end{tabular}

When reading this table we are interested in the results of the "Pearson Chi-Square" row.

We can see here that $\chi^{\Lambda^{2}}=10.737, p=0.29$. This tells us that there is no statistically significant association between side effects of immunotherapy and control and Hospitals;

\begin{tabular}{|c|c|c|c|c|c|c|c|}
\hline & & 1 & 2 & 3 & 4 & 5 & Tota \\
\hline \multirow{4}{*}{ Hospital Name } & Apollo & 5 & 5 & 4 & 0 & 4 & 18 \\
\hline & Basavaturakam Indo American & 11 & 6 & 0 & 1 & 3 & 21 \\
\hline & Omega & 7 & 7 & 4 & 3 & 2 & 23 \\
\hline & Yashodha & 2 & 4 & 3 & 3 & 6 & 18 \\
\hline \multicolumn{2}{|r|}{ Total } & 25 & 22 & 11 & 7 & 15 & 80 \\
\hline
\end{tabular}

This table allows us to understand that Hospitals VS success rate of (\%) immunotherapy and effective to 1, 2, 3, 4 and 5 .

\section{Hypothesis}

$\mathrm{Ho}_{13}=$ There is no significant association between the success rate of $(\%)$ immunotherapy and effective and Hospitals

$\mathrm{H} 1_{13}=$ There is a significant association between the success rate of $(\%)$ immunotherapy and effective and Hospitals

\begin{tabular}{|c|c|c|c|}
\hline \multicolumn{4}{|l|}{ Chi-Square Tests } \\
\hline & Value & Df & $\begin{array}{c}\text { Asymp. Sign } \\
\text { (2-sided) }\end{array}$ \\
\hline Pearson Chi-Square & $17.186^{a}$ & 12 & .143 \\
\hline $\mathrm{N}$ of Valid Cases & 80 & & \\
\hline
\end{tabular}

When reading this table we are interested in the results of the "Pearson Chi-Square" row.

We can see here that $\chi^{\Lambda^{2}}=17.186, p=0.14$. This tells us that there is no statistically significant association between the success rate of (\%) immunotherapy and effective and Hospitals

\begin{tabular}{l|l|c|c|c|c|} 
11. Would you like to suggest any improvement in existing immunotherapy \\
\hline & & $\mathbf{1}$ & $\mathbf{2}$ & $\mathbf{3}$ & Total \\
\hline \multirow{4}{*}{ Hospital Name } & Apollo & 6 & 9 & 3 & 18 \\
\cline { 2 - 7 } & Basavaturakam Indo american & 7 & 7 & 7 & 21 \\
\cline { 2 - 7 } & Omega & 7 & 10 & 6 & 23 \\
\hline Total & Yashodha & 7 & 5 & 6 & 18 \\
\hline
\end{tabular}

This table allows us to understand that Hospitals VS you like to suggest on existing immunotherapy to 1, 2 and 3.

\section{Hypothesis}

$\mathrm{Ho}_{14}=$ There is no significant association between you like to suggest on existing immunotherapy and Hospitals

$\mathrm{H} 1_{14}=$ There is a significant association between you like to suggest on existing immunotherapy and Hospitals

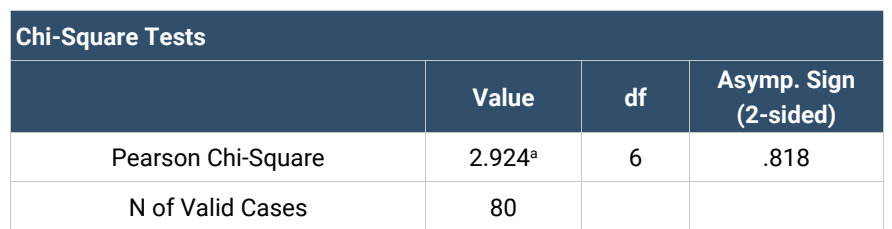

When reading this table we are interested in the results of the "Pearson Chi-Square" row.

We can see here that $\chi^{\Lambda^{2}}=2.924, p=0.81$. This tells us that there is no statistically significant association between you like to suggest on existing immunotherapy and Hospitals.

\section{Conclusion}

Based on primary and secondary research the researcher can conclude that a few null hypotheses were estimated previously, their results after the data analysis were estimated. Doctors still need long term studies and observations on immunotherapy to have a specific protocol instead of a global protocol because the immunotherapy came into India in the year between 2013 to 2014. The percentage of people willing to undergo immunotherapy treatment is less. The doctors may choose immunotherapy molecules based on the economic factors and its cost involved in the therapy. They mainly choose immunotherapy because it can be given with any other therapy and has good potential action. In the future, the success rate of immunotherapy will be increasing if it can be used along with any other therapy i.e combination therapy. This would be the upcoming future in immunotherapy. The achievement saw with disease immunotherapy medicines stresses the significance of understanding tumor immunology-especially the parts of tumor antigens and the immunosuppressive tumor microenvironment. Fortunately, numerous new immunotherapy techniques and specialists are being explored and tried in clinical preliminaries, which will ideally give new compelling medicines to patients living with backslid or obstinate malignancies.

\section{References}

1. Raval RR, Sharabi AB, Walker AJ, Drake CG, Sharma P (2014) Tumor immunology and cancer immunotherapy: Summary of the 2013 SITC primer. J Immunother Cancer 2: 14. Link: http://bit.ly/3nCcqgr

2. Thappa D, Chiramel M (2016) Evolving role of immunotherapy in the treatment of refractory warts. Indian Dermatology Online Journal 7: 364. Link: http://bit.ly/39mryck

3. Oiseth SJ, Aziz MS (2017) Cancer immunotherapy: a brief review of the history, possibilities, and challenges ahead. Journal of Cancer Metastasis and Treatment 3: 250. Link: http://bit.ly/3oFxXWL

4. Yu Y, Cui J (2018) Present and future of cancer immunotherapy: A tumour microenvironmental perspective. Oncology Letters Spandidos 16: 4105-4113. Link: http://bit.ly/3owl80t 
5. Davis AA, Patel VG (2019) The role of PD-L1 expression as a predictive biomarker: An analysis of all US food and drug administration (FDA) approvals of immune checkpoint inhibitors. Journal for ImmunoTherapy of Cancer 7: 278. Link: http://bit.ly/3oCUle3

6. Quintana E, Shackleton M, Sabel MS, Fullen DR, Johnson TM, et al. (2008) Efficient tumour formation by single human melanoma cells. Nature 456: 593 598. Link: http://bit.ly/3oCpJid

7. Yang X, Zeng Q, Barlş M, Tezel G (2020) Transgenic inhibition of astroglial NF-kB restrains the neuroinflammatory and neurodegenerative outcomes of experimental mouse glaucoma. J Neuroinflammation 17: 252. Link: http://bit.ly/38Cp8Ym

8. Thappa DM, Chiramel MJ (2016) The evolving role of immunotherapy in the treatment of refractory warts. Indian Dermatol Online J 7: 364-370. Link: http://bit.ly/3i2t5sp

9. Jackson HA, Jackson MW, Coblentz L, Hammerberg B (2003) Evaluation of the clinical and allergen-specific serum immunoglobulin $E$ responses to oral challenge with cornstarch, corn, soy and a soy hydrolysate diet in dogs with a spontaneous food allergy. Vet Dermatol 4: 181-187. Link: http://bit.ly/3q3ZTUC

10. Vinuya RZ (2000) Specific Allergen Immunotherapy for Allergic Rhinitis and Asthma. Pediatric Annals 29: 425-432. Link: http://bit.ly/38zPQR4
11. Alsaab HO, Sau S, Alzhrani R, Tatiparti K, Bhise K, et al. (2017) PD-1 and PDL1 checkpoint signalling inhibition for cancer immunotherapy: mechanism, combinations, and clinical outcome. Front Pharmacol 8: 561. Link: http://bit.ly/39uct98

12. Narváez J, Juarez-López P, LLuch J, Narváez JA, Palmero R, et al. (2018) Rheumatic immune-related adverse events in patients on anti-PD-1 inhibitors: fasciitis with myositis syndrome as a new complication of immunotherapy. Autoimmun Rev 17: 1040-1045. Link: http://bit.ly/38yCHYA

13. Alsaab HO, Sau S, Alzhrani R, Tatiparti K, Bhise K, et al. (2017) PD-1 and PDL1 checkpoint signalling inhibition for cancer immunotherapy: mechanism, combinations, and clinical outcome. Front Pharmacol 8: 561. Link: http://bit.ly/39uct98

14. Ma W, Gilligan BM, Yuan J, Li T (2016) Current status and perspectives in translational biomarker research for PD-1/PD-L1 immune checkpoint blockade therapy. Journal of Haematology \& Oncology 9: 47. Link: http://bit.ly/3bBW5WN

15. Andrews LP, Yano H, Vignali DA (2019) Inhibitory receptors and ligands beyond PD-1, PD-L1 and CTLA-4: breakthroughs or backups. Nature immunology 20:1425-1434. Link: https://go.nature.com/2XwGKyh.

\section{Discover a bigger Impact and Visibility of your article publication with}

\section{Peertechz Publications}

\section{Highlights}

* Signatory publisher of ORCID

* Signatory Publisher of DORA (San Francisco Declaration on Research Assessment)

* Articles archived in worlds' renowned service providers such as Portico, CNKI, AGRIS, TDNet, Base (Bielefeld University Library), CrossRef, Scilit, J-Gate etc.

* Journals indexed in ICMJE, SHERPA/ROMEO, Google Scholar etc.

* OAI-PMH (Open Archives Initiative Protocol for Metadata Harvesting)

* Dedicated Editorial Board for every journa

* Accurate and rapid peer-review process

* Increased citations of published articles through promotions

* Reduced timeline for article publication

Submit your articles and experience a new surge in publication services (https://www.peertechz.com/submission).

Peertechz journals wishes everlasting success in your every endeavours.

Copyright: @ 2021 Kumar NR, et al. This is an open-access article distributed under the terms of the Creative Commons Attribution License, which permits unrestricted use, distribution, and reproduction in any medium, provided the original author and source are credited. 